Bull. Mater. Sci., Vol. 22, No. 2, April 1999, pp. 115-119. (C) Indian Academy of Sciences.

\title{
Effect of hydroxyl content on the physical properties of calcium metaphosphate glasses
}

\author{
B KARMAKAR*, P KUNDU, ANUP K CHAUDhURI, K ANNAPURNA, A KUMAR and \\ R N DWIVEDI \\ Glass Technology Section, Central Glass and Ceramic Research Institute, Calcutta 700 032, India
}

MS received 7 October 1998; revised 9 February 1999

\begin{abstract}
The hydroxyl (OH) content of calcium metaphosphate glasses has been controlled in the range $50-800 \mathrm{ppm}$ by melting calcium dihydrogen phosphate in air, under vacuum and with fluoride addition. Density, refractive index and glass transition temperature of the glasses increase with decrease in $O H$ content while the coefificient of thermal expansion remains almost unchanged. With gradual decrease in $O H$, the UV cutoff initially shifts towards shorter and finally towards longer wavelengths. IR spectroscopic study shows that the $\mathrm{OH}$ groups exist exchusively in the hydrogen bonded states. Correlations of the glass properties with $O H$ content have been explained in terms of structural rearrangement leading to the change in $P-O$ bond length and $\mathrm{O}-\mathrm{P}-\mathrm{O} / \mathrm{P}-\mathrm{O}-\mathrm{P}$ bond angles of the $\mathrm{PO}_{4}$ tetrahedral units of $\left(\mathrm{PO}_{3}^{-}\right)_{n}$ chains. These changes are caused due to conversion of non-bridging oxygens (NBOs) of the H-bonded OH groups into bridging oxygens (BOs) during progress of dehydroxylation.
\end{abstract}

Keywords. Phosphate glass; hydroxyl content; glass properties; IR spectra; hydrogen bond.

\section{Introduction}

Unintentional water enters into the glasses as impurity during melting from the raw materials and surrounding humid atmospheres. In oxide glasses, low residual water $\left(<2 \times 10^{3} \mathrm{ppm}\right)$ exists entirely in the form of hydroxyl (OH) groups (Davis and Tomozawa 1996). This $\mathrm{OH}$ group behaves as modifier like alkali and alkaline earth metal ions by terminating the polymeric chains of the glass network (Shelby and McVay 1976; Bartholomew 1982; Brow et al 1990; Gomez et al 1997). In presence of nonbridging oxygens (NBOs), it exists both as unbonded (i. e. free $\mathrm{OH}$ ) and hydrogen bonded (H-bonded OH) states (Scholze 1959, 1966; Adams 1961). Alteration of glass structure by various types and concentrations of $\mathrm{OH}$ group is well established (Davis and Tomozawa 1995; Jewell and Aggarwal 1995; Mercier et al 1998). Physical properties of a glass are governed by its structure (Gaskell 1997). Thus, variation of glass properties is expected with structural modifications imparted by the $\mathrm{OH}$ groups. Several studies have been published on the effects of high $\mathrm{OH}$ content on the physical properties of oxide glasses (Shelby and McVay 1976; Bartholomew 1982; Abe 1983; Tomozawa 1985; Toratani et al 1987), but only a few concern about their low $\mathrm{OH}$ content (Arriagada et al 1987). In this paper, we report the influence of low $\mathrm{OH}$ content (50-800 ppm) on the optical and thermal properties of calcium metaphosphate glasses.

*Author for correspondence

\section{Experimental}

\subsection{Preparation of glass}

Calcium metaphosphate glasses with varying $\mathrm{OH}$ content were prepared by melting calcium dihydrogen phosphate, $\mathrm{Ca}\left(\mathrm{H}_{2} \mathrm{PO}_{4}\right)_{2} \mathrm{H}_{2} \mathrm{O}$ (Alfa) at $1100^{\circ} \mathrm{C}$ in a platinum crucible in air, under vacuum $\left(4 \times 10^{-3} \mathrm{~mm} \mathrm{Hg}\right)$ and by adding calcium fluoride, $\mathrm{CaF}_{2}$. Molten glasses were cast in preheated graphite moulds and quenched in air. All the glasses were annealed at about $20^{\circ} \mathrm{C}$ below the glass transition temperature.

\subsection{Measurement of glass properties}

Infrared (IR) absorption spectra in the range 1500 $4000 \mathrm{~cm}^{-1}$ of the glasses were recorded on a Perkin-Elmer 1615 FTIR spectrometer at $4 \mathrm{~cm}^{-1}$ resolution. The $\mathrm{OH}$ content of the glasses was calculated from the IR spectra following the method described in Ebendorff-Heidepriem et al (1993). The ultraviolet (UV) spectra of the samples were examined utilizing a Hitachi (Model U 3210) double beam UV-VIS spectrophotometer. Optically polished glass samples of $1.0 \pm 0.02 \mathrm{~mm}$ thickness were used in these measurements.

Density (d) of the glasses was measured by the Archimedes method at $25 \pm 0.5^{\circ} \mathrm{C}$ using kerosene as the immersion liquid. The refractive index $\left(n_{\mathrm{v}}\right.$, at $\left.\lambda=587.6 \mathrm{~nm}\right)$ was measured with the Pulfrich-Refractometer (Model 
PR2). Glass transition temperature $\left(T_{\mathrm{g}}\right)$ and coefficient of linear thermal expansion $(\alpha)$ of the glasses were determined from the dilatometric thermogram recorded with an Orton Automatic Recording Dilatometer.

\section{Results and discussion}

\subsection{IR spectra}

The IR spectra of some representative calcium metaphosphate glasses with $\mathrm{OH}$ content has been shown in figure 1. It can be seen that there are three distinct bands at around 2900,2340 and $1750 \mathrm{~cm}^{-1}$ which gradually decrease in intensity with the progress of dehydroxylation. They are thought to be $\mathrm{OH}$ group related bands. In silicate glasses, the band due to free $\mathrm{OH}$ group has been observed at about $3570 \mathrm{~cm}^{-1}$. The bands due to weakly associated $\mathrm{H}$-bond of middle $\mathrm{OH}$ and strongly bound $\mathrm{H}$-bond of isolated or end $\mathrm{SiO}_{4}$ tetrahedral $\mathrm{OH}$ with NBOs have been observed at around 3000 and $2350 \mathrm{~cm}^{-1}$, respectively (Scholze 1959, 1966). A very strong $\mathrm{H}$-bonded band in the range $1650-1750 \mathrm{~cm}^{-1}$ has also been found to develop in the cases of organophosphonic and phosphonous acids ending with $>\mathrm{P}(=\mathrm{O}) \mathrm{OH}$ group (Braunholtz et al 1959). It is known that metaphosphate glasses consist of mainly linear chains of polyphosphate anions which are connected to one another by the ionic bonds to the modifier cations (Van Wazer 1950). Thus, all of the $\mathrm{OH}$ groups of the calcium metaphosphate glasses are thought to be due to H-bonded states. The bands at around 2900,2340 and $1750 \mathrm{~cm}^{-\dagger}$ have been assigned to $\mathrm{O}-\mathrm{H}$ stretching vibration of weakly $\mathrm{H}$-bonded middle $\mathrm{OH}$ groups with middle NBOs of the phosphate chains, strongly $\mathrm{H}$-bonded isolated and/or end $\mathrm{PO}_{4}$ tetrahedral $\mathrm{OH}$ groups with middle $\mathrm{NBO}$ (of an another chain), and very strongly $\mathrm{H}$-bonded end $\mathrm{OH}$ groups with end NBOs, respectively.

$A$ band at around $2170 \mathrm{~cm}^{-1}$ not observed in high $\mathrm{OH}$ containing glasses rather has been found to develop with the progress of dehydroxylation (figure 1). Perhaps, it was hidden in the tail of strong absorption band at around $2340 \mathrm{~cm}^{-1}$ of strongly $\mathrm{H}$-bonded $\mathrm{OH}$ group. This band has been assigned to the first overtone of $\nu_{\mathrm{ss}}(\mathrm{OPO})$ and/or combinational band of $\nu_{\mathrm{as}}(\mathrm{OPO})+v_{\mathrm{as}}(\mathrm{POP})$ fundamentals of $\mathrm{PO}_{4}$ tetrahedra; the fundamental band of $v_{\mathrm{as}}(\mathrm{OPO}), v_{\mathrm{ss}}(\mathrm{OPO})$ and $\nu_{\mathrm{as}}(\mathrm{POP})$ develops at around 1280,1100 and $900 \mathrm{~cm}^{-1}$, respectively. Development of the $2170 \mathrm{~cm}^{-1}$ band with dehydroxylation is brought about by structural rearrangement leading to the change in $\mathrm{P}-\mathrm{O}$ bond distance and $\mathrm{O}-\mathrm{P}-\mathrm{O}$ or $\mathrm{P}-\mathrm{O}-\mathrm{P}$ bond angles. Brow et al (1990) showed by MAS NMR study of sodium phosphate glasses that decrease in NBOs (i.e. $\mathrm{Na}_{2} \mathrm{O}+\mathrm{H}_{2} \mathrm{O}$ ) causes increase in average $\pi$-character of the $\mathrm{P}-\mathrm{O}$ bonds which results in decrease in $\mathrm{P}-\mathrm{O}$ bond distance due to $\pi$-bond shortening.

\section{$3.2 U V$ cutoff}

Dependence of UV cutoff on the $\mathrm{OH}$ content of the glasses has been shown in figure 2. It shows two distinct regions. In region I, between 110 and $720 \mathrm{ppm} \mathrm{OH}$ content, the UV cutoff shifts towards shorter wavelength. This is caused due to removal of weakly associated $\mathrm{H}$-bonded chain middle $\mathrm{OH}$ groups which is supported by the decrease in intensity of the $2900 \mathrm{~cm}^{-1}$ band with dehydroxylation (see figure 1). In region II, between 60 and $110 \mathrm{ppm} \mathrm{OH}$ content, the UV cutoff shifts towards longer wavelength. This effect has been brought about by the removal of very strongly $\mathrm{H}$-bonded chain end and isolated $\mathrm{PO}_{4}$ tetrahedral $\mathrm{OH}$ groups as evident from the intensity decrease of the bands at 2340 and $1750 \mathrm{~cm}^{-1}$ (see figure 1). These results are in accordance with those obtained in calcium metaphosphate glasses

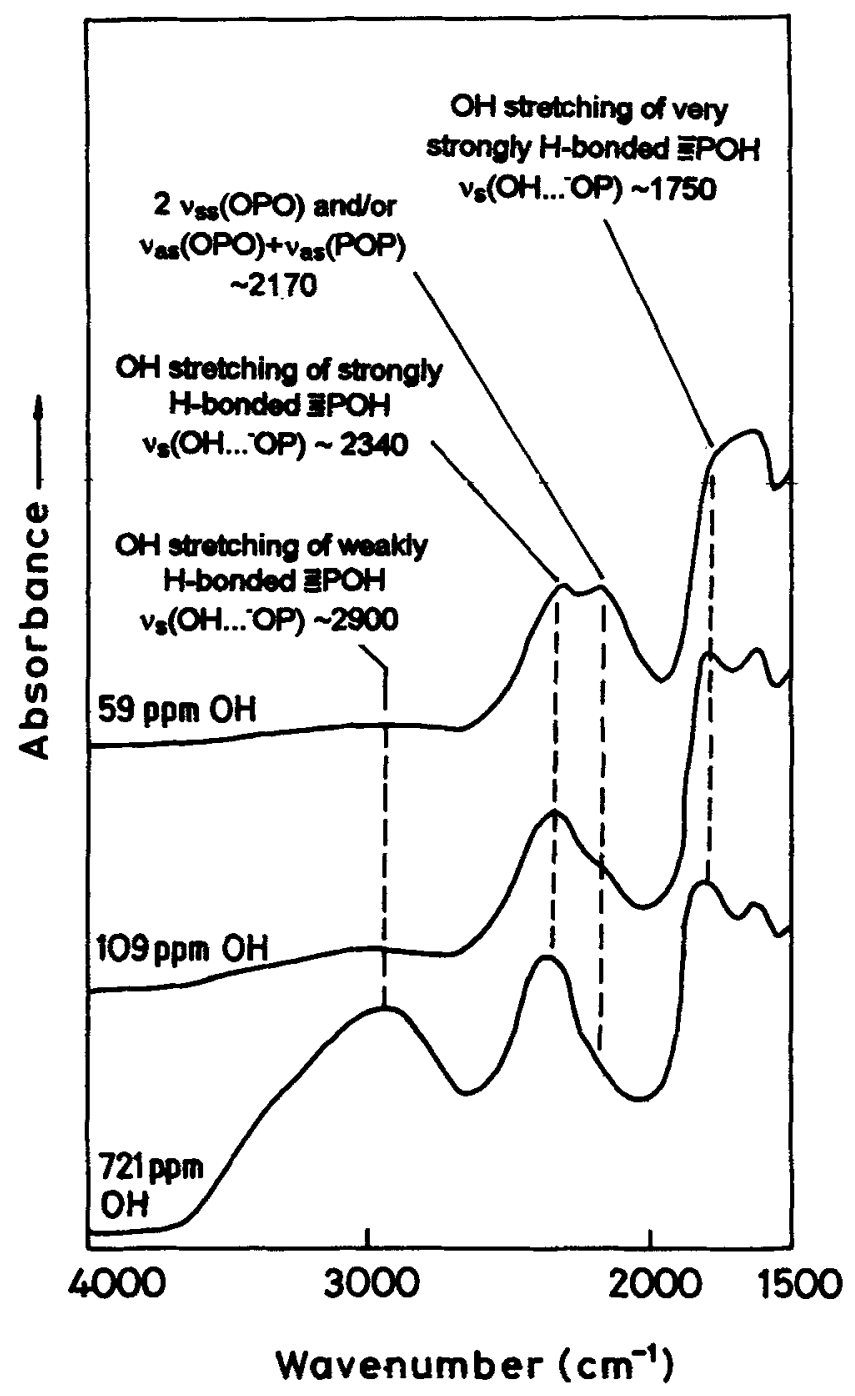

Figure 1. Infrared absorbance spectra of calcium metaphosphate glasses with varying $\mathrm{OH}$ content. 
(Arriagada et al 1987). Similar effect has also been observed when network modifying cations are added to vitreous $\mathrm{P}_{2} \mathrm{O}_{5}$ (Kordes and Worster 1959; Kordes 1965). In these glasses, with addition of $\mathrm{Na}^{+}$or $\mathrm{Ba}^{2+}$ the UV absorption edge shifts towards shorter wavelengths for low concentrations (up to around $25 \mathrm{~mol} \%$ ) and for high concentrations (above around $25 \mathrm{~mol} \%$ ), it shifts towards longer wavelengths.

Further, in region $I$, it is assumed that more $\mathrm{P}-\mathrm{O}-\mathrm{P}$ bonds, i.e. bridging oxygens (BOs), are generated with the removal of middle $\mathrm{OH}$ groups (Gomez et al 1997) and due to lower microscopic basicity, $\lambda$ (Duffy and Ingram 1976), of the $\mathrm{P}-\mathrm{O}-\mathrm{P}$ bond $(\lambda=0.25)$ than that of $\mathrm{P}-\mathrm{O}-\mathrm{H}$ bond $(\lambda=0.32)$, the UV cutoff shifts towards shorter wavelengths. Whereas in region II, the average $\pi$-character of the $\mathrm{P}-\mathrm{O}$ bonds increases as the end $\mathrm{OH}$ group decreases (Brow et al 1990), thereby increasing the optical basicity (Duffy and Grant 1975) which causes the shift of the UV cutoff towards longer wavelengths. The increase in intensity of the IR band at around $2170 \mathrm{~cm}^{-1}$ supports the formation of $\mathrm{P}-\mathrm{O}-\mathrm{P}$ and $\mathrm{O}-\mathrm{P}=\mathrm{O}$ bonds with dehydroxylation $(\$ 3.1)$.

\subsection{Density and refractive index}

The influence of $\mathrm{OH}$ content on density and refractive index has been shown in figures 3 and 4 , respectively. It is seen that both these properties increase simultaneously as the $\mathrm{OH}$ content decreases and clearly exhibit two regions. In the region between 0 and $200 \mathrm{ppm} \mathrm{OH}$ content they increase rapidly due to the removal of end group $\mathrm{OH}$ whereas in the region between 200 and $800 \mathrm{ppm} \mathrm{OH}$ content they increase slowly due to the

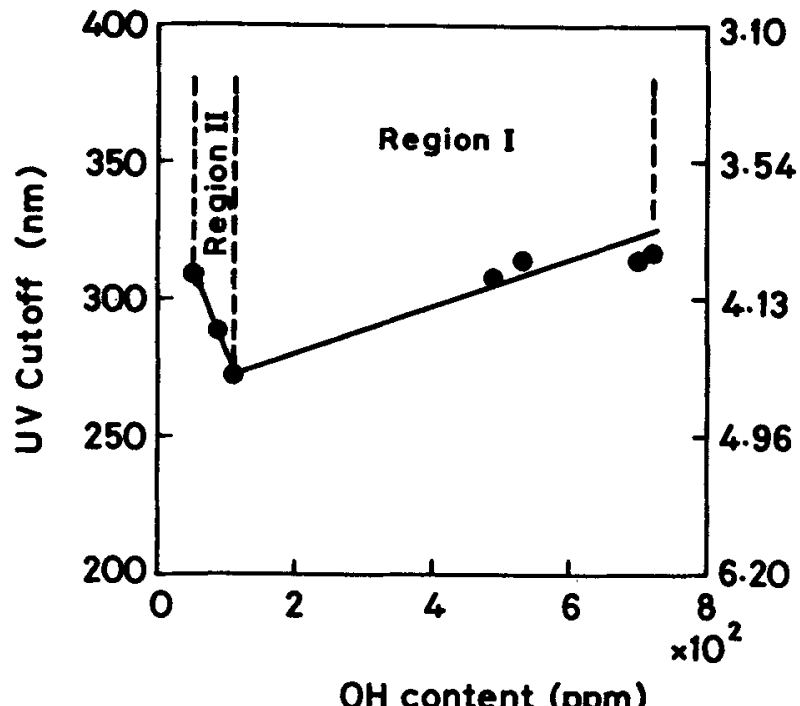

Figure 2. Dependence of UV cutoff of the glasses on $\mathrm{OH}$ content. removal of middle group $\mathrm{OH}$. These simultaneous variations of density and refractive index with $\mathrm{OH}$ content agree well with the direct variation relationship of density and refractive index of a glass (Cohen and Roy 1965). IR spectra depict that all of the $\mathrm{OH}$ groups are in the $\mathrm{H}$-bonded states (figure 1) and the glasses attain the denser structures with dehydroxylation through the formation of bridging oxygens (BOs) of the P-O-P bonds as concluded due to increase in intensity of the IR bands at around $2170 \mathrm{~cm}^{-1}(\S 3.1)$.

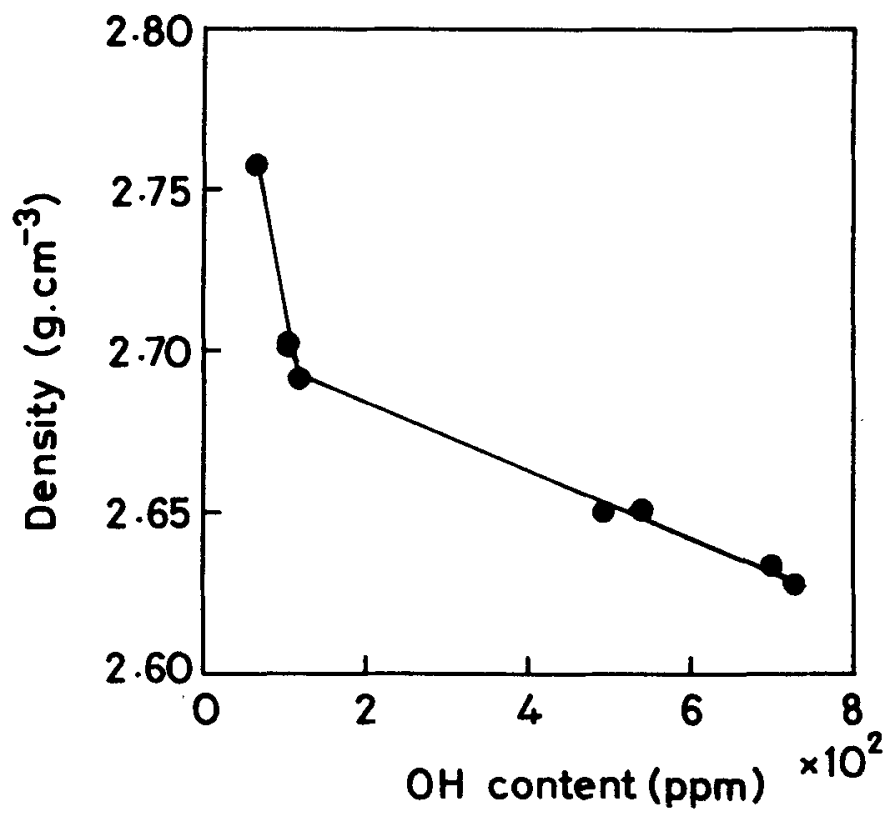

Figure 3. Dependence of density (d) of the glasses on $\mathrm{OH}$ content.

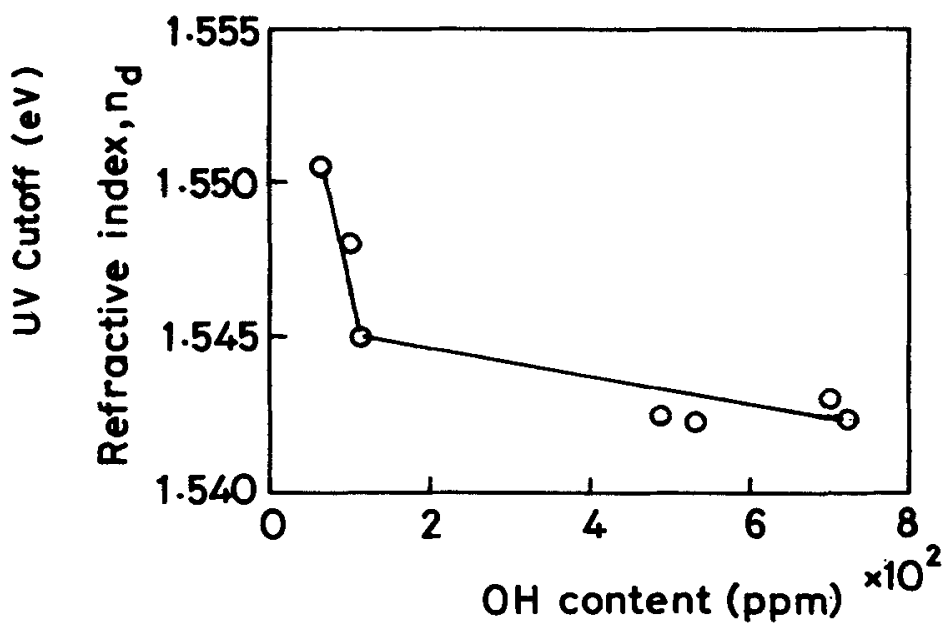

Figure 4. Dependence of refractive index $\left(n_{\mathrm{d}}\right)$ of the glasses on $\mathrm{OH}$ content. 


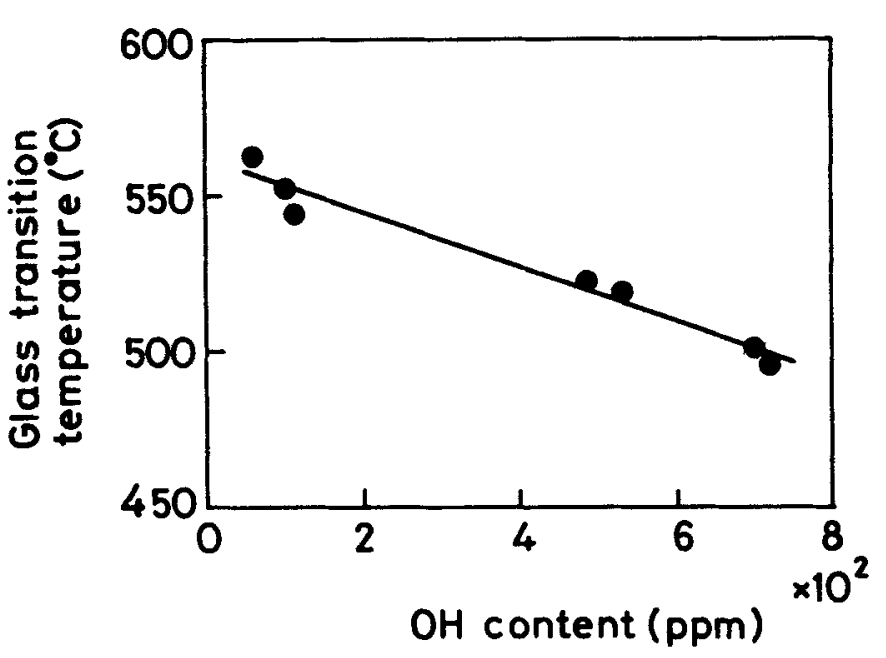

Figure 5. Dependence of glass transition temperature $\left(T_{\mathrm{g}}\right)$ on $\mathrm{OH}$ content.

\subsection{Glass transition temperature and coefficient of linear thermal expansion}

Dependence of glass transition temperature, $T_{\mathrm{g}}$, on the $\mathrm{OH}$ content has been shown in figure 5 . It is seen that the glass transition temperature increases with decrease in $\mathrm{OH}$ content which is caused due to strengthening of the glass structure. This tightening of structure is also reflected by the increase in intensity of the IR band at $2170 \mathrm{~cm}^{-1}(\S 3.1)$. The effect is analogous to the alkali effect on the glass properties which has been explained with the concept of NBO formation on alkali oxide addition (Brow et al 1990). Results of this study agree well with those obtained with decrease in $\mathrm{OH}$ content in calcium metaphosphate (Abe 1983; Arriagada et al 1987) and sodium trisilicate (Shelby and McVay 1976; Tomozawa et al 1983) glasses.

The effect of $\mathrm{OH}$ content on the coefficient of linear thermal expansion, $\alpha\left(30-300^{\circ} \mathrm{C}\right)$, has been shown in figure 6. Expansivity of the glasses is virtually unaffected by the presence of negligible amount of $\mathrm{OH}$ groups or to a small extent to be measured by the standard dilatometer used in this investigation. However, there is a good agreement of these results with those obtained in calcium metaphosphate (Abe 1983) and sodium trisilicate (Shelby and McVay 1976) glasses.

\section{Conclusions}

Calcium metaphosphate glasses with varying $\mathrm{OH}$ contents have been obtained by melting in air, vacuum and with fluoride addition. Density, refractive index and glass transition temperature have been found to increase with decrease in $\mathrm{OH}$ content while the coefficient of linear

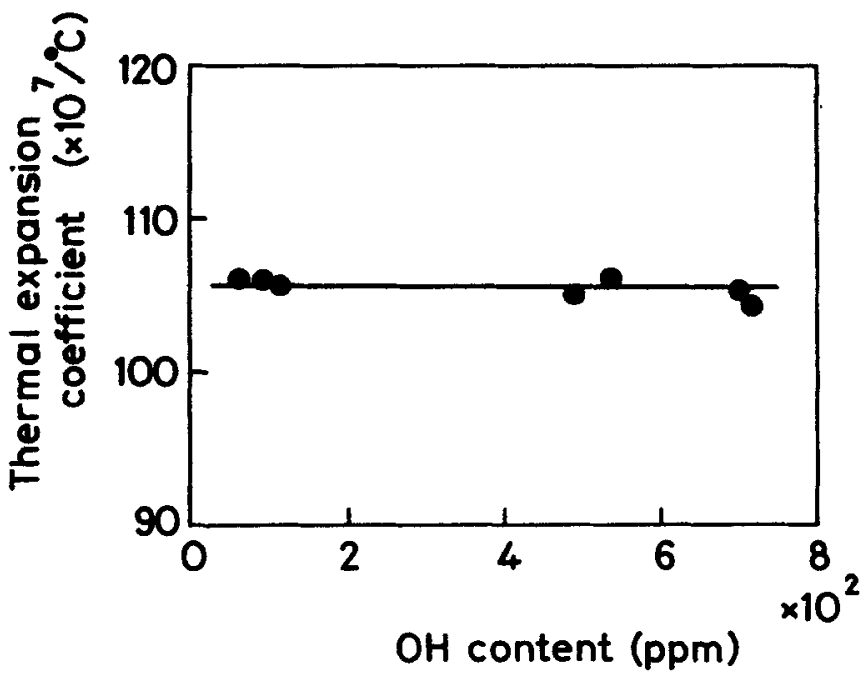

Figure 6. Dependence of coefficient of linear thermal expansion (a) of the glasses on $\mathrm{OH}$ content.

thermal expansion remains almost unaffected. The UV cutoff, with decrease in $\mathrm{OH}$ content, shifts initially to the shorter wavelength and then towards longer wavelengths. IR spectroscopic study show the presence of exclusively $\mathrm{H}$-bonded states of the $\mathrm{OH}$ groups and the formation of $\mathrm{O}-\mathrm{P}=\mathrm{O}$ and $\mathrm{P}-\mathrm{O}-\mathrm{P}$ bonds with the progress of dehydroxylation. Variation of glass properties with $\mathrm{OH}$ content is brought about by structural rearrangement leading to the change in $\mathrm{P}-\mathrm{O}$ bond length and $\mathrm{O}-\mathrm{P}-\mathrm{O}$ / $\mathrm{P}-\mathrm{O}-\mathrm{P}$ bond angles during dehydroxylation.

\section{References}

Abe $\mathrm{Y} 1983$ in Topics in phosphorous chemistry (eds) M Grayson and E J Griffith (New York: John Wiley) Vol. 11, p. 20

Adams R V 1961 Phys: Chem. Glasses 239

Arriagada J C, Burckhardt W and Feltz A 1987 J. Non-Cryst. Solids 91375

Bartholomew R F 1982 in Treatise on materials science and technology (eds) M Tomozawa and R H Doremus (New York: Academic Press) Vol. 22, p. 75

Braunholtz J T, Hall G E, Mann F G and Shepard N $1959 \mathrm{~J}$. Chem. Soc. 868

Brow R K, Kirkpatrick R J and Turner G L 1990 J. Non-Cryst. Solids 11639

Cohen H M and Roy R 1965 Phys. Chem. Glasses 6149

Davis K M and Tomozawa M 1995 J. Non-Cryst. Solids 185 203

Davis K M and Tomozawa M 1996 J. Non-Cryst. Solids 201 177

Duffy J A and Ingram M D 1976 J. Non-Cryst. Solids 21373

Duffy J A and Grant R J 1975 Phys. Chem. Glasses 16124

Ebendorff-Heidepriem H, Seeber W and Ehrt D 1993 J. Non-Cryst. Solids 16374

Gaskell P H 1997 J. Non-Cryst. Solids 2221

Gomez F, Vast P, Llewellyn Ph. and Rouquerol F $1997 \mathrm{~J}$. Non-Cryst. Solids 222415 
Jewell J M and Aggarwal I D 1995 J. Non-Cryst. Solids 181 189

Kordes E 1965 Glastechn. Ber. 38242

Kordes E and Worster E 1959 Glastechn. Ber. 32267

Mercier C, Montagne L, Sfihi H, Palavit G, Boivin J C and Legrand A P 1998 J. Non-Cryst. Solids 224163

Scholze H 1959 Glastechn. Ber. 32142

Scholze H 1966 Glass Ind. 47622
Shelby J E and McVay G L 1976 J. Non-Cryst. Solids 20 439

Tomozawa M 1985 J. Non-Cryst. Solids 73197

Tomozawa M, Takata M, Acocella J, Watson E B and Takamori T 1983 J. Non-Cryst. Solids 56343

Toratani H, Meissner H E and Izumitani T $1987 \mathrm{~J}$. Non-Cryst. Solids $95 \& 96701$

Van Wazer J R 1950 J. Am. Chem. Soc. 72644 